\title{
Comparison of health behaviors among students of Iranian medical and human sciences universities
}

\author{
Masoumeh Shohani ${ }^{1}$, Mahboobeh Rasouli ${ }^{2}$
}

${ }^{1}$ Ph.D. of Nursing, Assistant Professor, Department of Nursing, Faculty of Allied Medical Sciences, Ilam University of Medical Sciences, Ilam, Iran

${ }^{2}$ Ph.D. of Biostatics, Assistant Professor, Department of Biostatics, Public Health School, Iran University of Medical Sciences, Tehran, Iran

\section{Type of article: Original}

\begin{abstract}
Background and aim: Health risk behaviors are major and threatening problems of societies. The aim of this study was to determine and compare health behaviors among students of Iranian medical and human sciences universities.

Methods: In this cross-sectional study, 570 senior medical and human sciences students of Ilam universities (Ilam, Iran) were selected during the period between October 2015 and October 2016, using the stratified random sampling method. The research tool was the self-assessment health questionnaire which consists of personal information, understanding the concept of health and health behaviors. Descriptive statistics and Mann-Whitney $\mathrm{U}$, independent samples t-test and Pearson product-moment correlation tests were used in SPSS version 16.

Results: The scores obtained by both groups of medical sciences and human sciences students were low. There was no significant relationship between field of study and the score of understanding the concept of health $(p=0.289)$; but the relationship between field of study and the score on health behaviors $(p=0.001)$ and between health behaviors and understanding the concept of health were significant for both the students of medicine $(\mathrm{r}=0.259, \mathrm{p}=0.01)$ and the students of human sciences $(\mathrm{r}=0.493, \mathrm{p}=0.001)$.

Conclusion: Students' health behaviors were not at a desirable level. Conducting interventions in the form of research projects have been recommended.

Keywords: Behavior, Health, Iran, Student
\end{abstract}

\section{Introduction}

\subsection{Background and study logic}

According to the World Health Organization, health is one of the indexes of development for countries (1). Health promotion is a basic human need (2). Health behaviors and lifestyle are the most important factors in preventing disease and death and promoting health (3). Health behaviors are those behaviors that affect people's health. Searching for health-related information, referring to a physician or dentist for a general examination, immunization, exercise, proper diet, wearing a seat belt while driving, healthy sexual relations and sensitization towards health status are health behaviors (4). One of the critical periods regarding the formation and performance of health promoting behaviors is adolescence and early youth, i.e. the ages of 15-24 (5). Behaviors that are formed in this period continue to affect individuals in later periods of life. Despite the fact that the youth are very important in the formation of the future generation since they are at a relatively healthy age in their lives, they are not taken into consideration as a priority in the health promoting efforts around the world (6). This is at a time when adolescents scarcely think about life skills or social skills required for health management and management of the emotions.

\section{Corresponding author:}

Assistant Professor Dr. Mahboobeh Rasouli, Department of Biostatics, Public Health School, Iran University of Medical Sciences, Tehran, Iran. Tel: +98.9125763631, Fax:+98.8432227114, Email: rasouli2007@yahoo.com

Received: February 05, 2017, Accepted: March 01, 2018, Published: May 2018

iThenticate screening: February 24, 2018, English editing: March 12, 2018, Quality control: April 10, 2018

This article has been reviewed / commented by three experts

Funding / research project approval: 22/40/94/5831

Ethics approval: ir.medilam.rec.1394.180

(C) 2018 The Authors. This is an open access article under the terms of the Creative Commons Attribution-NonCommercialNoDerivs License, which permits use and distribution in any medium, provided the original work is properly cited, the use is non-commercial and no modifications or adaptations are made. 
Thus, they could become upset if they were given the responsibility to take care of themselves. They might even become depressed when they are left alone to face difficulties (7). One of the vital periods during one's youth is the time when he/she is a university student. It is in fact an exciting period full of challenges for the students. In this period, young people gradually accept responsibility for their health as they grow physically, mentally, socially and sexually. This transient period is the best time for the creation of healthy behavior (8). According to Wang et al., good behavior regarding health promoting can be formed in one's character if they live with such behavior in the early years of their lives (9). Entering university is accompanied by special emotions that can influence a student's physical and mental health. Due to special conditions of universities including being away from one's family, entering a big and stressful place, financial problems and not having enough money, much course work, competition with classmates, etc. students are susceptible to the loss of their physical and mental health (10). Studies show that there are many students who experience dangerous acts and situations such as alcohol and tobacco consumption, lack of body movement and unhealthy diet (11). The results of a study conducted by Hajian et al. (12) shows that the prevalence of physical involvement with others (violence) during a recent year was $33.3 \%$ current cigarette smoking $13.7 \%$, overweight and obesity $25.6 \%$, physical inactivity $15.3 \%$ and drug use during the recent year $0.3 \%$. In the study performed by Garmaroudi et al. (13), it was shown that $20.2 \%$ of the subjects had relationships with the opposite sex, $7.8 \%$ had experienced tobacco products, $7.4 \%$ consumed alcohol and $2 \%$ reported that they had used narcotics. Dangerous behavior in this age group might lead to individuals' inability in the productive ages and decrease one's length of life (14). University students were selected as the subjects of this study for several reasons. First of all is the fact that they are at an age when they are most teachable. Second, they are good models for a healthy lifestyle in society, especially the students of medicine, who are themselves, a sling loop in the health chain. In addition, being a student is a dynamic transitory period in everyone's life and it is the best time to create healthy behavior (15). Health-related behaviors are affected by many factors such as social norms, culture, media; national health policies and the environment (16), and mere education in medical sciences cannot reinforce healthy behavior in individuals.

\subsection{Objectives}

Considering the importance of the role of students' health behaviors in promoting community health, since basic information in any field can guide future research, this study aims compare health behaviors among students of medical and human sciences in Ilam universities.

\section{Material and Methods}

\subsection{Research design and participants}

This cross-sectional study was carried out among students of medical and human sciences in Ilam universities (Ilam, Iran), during the period between October 2015 and October 2016. The sample of the study consisted of 570 senior students, 117 of whom are students of medical sciences including those who study medicine, dentistry, nursing, midwifery and healthcare, and 453 are the students in non-medical majors including management, economics, physical education, engineering, foreign languages, literature and humanities.

\subsection{Selection criteria}

The inclusion criteria were being a fourth-year student and having the consent to participate in the research. Exclusion criteria were the guest and transfer students.

\subsection{Sampling}

Sampling was random and it took place in two stages. First, the numbers of medical and non-medical schools were determined and some of them were randomly selected. From among those schools, senior students were randomly selected from the name lists proportional to the number of students in each major. Thus, to determine the number of samples, the number of students in each major was asked by the office of education at each school first and then the number of the subjects to be included in the sample was defined proportional to the number of students who studied a particular major. After that, the researcher got the permission of the Medical Sciences University of Ilam to go to the field and give the questionnaires to the subjects.

\subsection{Research tools}

The research tool was a self-health assessment questionnaire designed by Shaban et al. (17) which consisted of three sections: 1) personal information 2) understanding the concept of health and 3) health behaviors in the physical, mental and social aspects. This questionnaire is a multi-dimensional evaluation of the behaviors that improve people's health. There are 94 items on the questionnaire, nine of which are related to demographic issues and 85 are 
about health-behaviors. Eleven of the items in the section on health-behaviors are about understanding the concept of health, and 74 are related to health-behaviors in physical, mental and social dimensions. The physical factors consisted of fitness (seven items), family background (six items), self-care and clinical care (eight items), eating habits (11 items), sexual behavior (three items), consumption of tobacco, cigarettes and narcotics (six items). The factors included in the mental and social dimensions were stress and social support (16 items), intellectual life and spiritual values (six items), the environment (seven items) and caution while driving (four items). To score, the Likert scale of zero to three (understanding the concept of health questions) was used for multiple choice items and zero and one were used for two-choice items (physical, mental and social dimensions). Reverse scoring was used for negative statements. It must be noted that the range of scores on understanding the concept of health is between $0-27$ and the range of scores on health behaviors is generally within 0-76. After collecting the questionnaires and scoring the responses without considering the omitted items, a score of less than 15 on understanding the health concept is considered weak, 15-19 is average, 20-24 is good and 25-27 is very good. Regarding health behaviors, a score of 40 and less is weak, 40-50 is average, and 51-60 is good and 61 and above is very good.

\subsection{Validity and reliability of the instrument}

Instrument validity and reliability for this study was estimated. To confirm the validity, the questionnaire was given to 10 faculty members at the faculty of nursing and midwifery at Ilam and Tabriz University of Medical Sciences. After some revisions, the questionnaire's internal consistency was ensured with Cronbach's alpha coefficient of $96 \%$. The reliability was estimated to be 0.83 , using test-retest method with an interval of 10 days.

\subsection{Statistical analysis}

The data were analyzed using SPSS 16 and descriptive statistics such as frequency distribution tables and frequency percentage and measures of central tendency such as mean and standard deviation. Normality of assumptions was evaluated using Kolmogorov-Smirnov test. In order to compare the scores on understanding the concept of health and health behaviors in the two groups of medical and non-medical students, independent-samples t-tests, MannWhitney U, and Pearson product-moment correction of correlation were used.

\subsection{Research ethics}

The participants' informed consent was also acquired emphasizing that the responses they gave would be kept confidential. It must be mentioned that this study was approved by the Committee of Ethics at Ilam University of Medical Sciences (Code of ethics ir.medilam.rec.1394.180).

\section{Results}

A total of 570 senior students participated in the study, 117 of whom were students of medical sciences, and 453 studied in human sciences. The students were within the age range of 18-30 with the mean of 22 and the standard deviation of 1.8 years. The demographic features of the students are given in Table 1. It must be mentioned that since more than $70 \%$ of the students did not respond to the sexual functioning items and more than $50 \%$ of them did not answer the two items on self-care, these items were deleted from the analyses. In cases where the percentage of non-responsiveness is less than $20 \%$, the values were estimated and replaced using statistical methods. Regarding the number of students in different groups, in the medical students' group, the majority of them (48.3\%) were students of nursing and in the non-medical students, the majority $(24.5 \%)$ were students of engineering. All the participants in the study were Muslims. Their fathers had elementary $(26 \%)$ and higher $(26 \%)$ education and their mothers who had primary education (33\%) allocated the highest percentage to themselves. The mean score for understanding the concept of health was $8.45 \pm 4.30$ for the students of medicine and it was $8.29 \pm 4.35$ for the students of other majors. The students of medicine and the students of human sciences had similar behaviors in all aspects and the mean scores for both groups are very close. However, regarding the aspects of self-care and medical care, eating habits, stress and social support, intellectual life and spiritual values, non-medical major students acquired higher scores. Among all aspects, significant differences were only observed in the aspects of self-care and clinical care $(\mathrm{p}=0.001)$, eating habits $(\mathrm{p}=0.011)$ and the living environment $(\mathrm{p}=0.001)$ based on Mann-Whitney $\mathrm{U}$ and $t$ tests. The score for understanding the concept of health for $92.5 \%$ of the students in non-medical majors and $96.5 \%$ of the students in medical majors was less than 15 , which is a very poor mark. The results of the independentsamples t-test show that there is not a significant relationship between one's field of study and his/her understanding of the concept of health. The score for health behaviors for $88.3 \%$ of the students in medical and $94.8 \%$ of the human sciences students was less than 40 which is a low mark. The results of the independent-samples t-test shows that there is a significant relationship $(\mathrm{p}=0.001)$ between health behaviors and one's field of study (Table 2$)$. The 
statistical relationship between the scores in the group of medical sciences and human sciences students is significant regarding Pearson's coefficient of correlation $(\mathrm{p}<0.001)$ (Table 3$)$.

Table 1. The relative and absolute frequencies for some student demographic characteristics in medical and nonmedical students.

\begin{tabular}{|c|c|c|c|}
\hline \multicolumn{2}{|l|}{ Status/features } & $\mathrm{n}$ & $\%$ \\
\hline \multirow[t]{3}{*}{ Gender } & Male & 154 & 27 \\
\hline & Female & 415 & 72.8 \\
\hline & Total & 569 & 99.8 \\
\hline \multirow[t]{3}{*}{ Marital status } & Married & 38 & 6.7 \\
\hline & Single & 527 & 92.5 \\
\hline & Total & 564 & 99.1 \\
\hline Religion & Islam & 570 & 100 \\
\hline \multirow[t]{3}{*}{ Field of study } & Medicine & 24 & 4.2 \\
\hline & Other & 453 & 72.5 \\
\hline & Total & 569 & 99.8 \\
\hline \multirow[t]{10}{*}{ Major } & Medicine & 24 & 4.2 \\
\hline & Nursing & 56 & 9.8 \\
\hline & Hygiene & 4 & 0.8 \\
\hline & Physical education & 10 & 1.8 \\
\hline & Management & 63 & 11.1 \\
\hline & Economics & 10 & 1.8 \\
\hline & Engineering & 111 & 19.5 \\
\hline & Language and literature & 82 & 14.4 \\
\hline & Other & 210 & 36.9 \\
\hline & Total & 570 & 100 \\
\hline \multirow[t]{5}{*}{ Place of residence } & Dormitory & 71 & 12.5 \\
\hline & Personal house & 458 & 80.4 \\
\hline & Rented house & 23 & 4 \\
\hline & Relations or friends' house & 11 & 1.9 \\
\hline & Total & 563 & 98.8 \\
\hline
\end{tabular}

Table 2. Absolute and relative frequency distributions for the scores on the health behaviors among medical and non-medical students

\begin{tabular}{|l|l|l|l|l|}
\hline \multirow{2}{*}{ Health behaviors / educational group } & \multicolumn{2}{l|}{ Medical sciences } & \multicolumn{2}{l|}{ Non-medical sciences } \\
\cline { 2 - 5 } & $\mathrm{n}$ & $\%$ & $\mathrm{n}$ & $\%$ \\
\hline Weak & 109 & 94.8 & 400 & 88.3 \\
\hline Average & 5 & 4.3 & 53 & 11.7 \\
\hline Good & 1 & 0.9 & 0 & 0 \\
\hline Total & 115 & 100 & 453 & 100 \\
\hline Mean (standard deviation) & $30.04(8.38)$ & $27.22(8.68)$ \\
\hline Comparison between mean scores & \multicolumn{4}{|l}{ Independent--samples t-tests $(\mathrm{p}=0.0010$} \\
\hline
\end{tabular}

Table 3. Mean, standard deviation and Pearson's coefficient of correlation for health behaviors and health-concept scores among medical and non- medical students

\begin{tabular}{|l|l|l|l|l|l|}
\hline Educational group / indexes & Mean & SD & Pearson's coefficient of correlation & p-value \\
\hline \multirow{2}{*}{ Medical students } & Health-behaviors score & 27.22 & 8.68 & $\mathrm{r}=0.259$ & 0.014 \\
\cline { 2 - 4 } & Health-concept score & 8.45 & 4.30 & & \\
\hline \multirow{2}{*}{ Non-medical students } & Health-promoting score & 30.04 & 8.38 & $\mathrm{r}=0.493$ & $<0.001$ \\
\cline { 2 - 4 } & Health-concept score & 8.29 & 4.36 & & \\
\hline
\end{tabular}

\section{Discussion}

Although more attention has been paid to the study of health-behaviors in university students in recent years, few studies have compared such behavior in the two groups of medical students and human sciences students. The 
results of this study indicate that the understanding of the health concept in both groups of students is weak and only in some cases, it is good or higher. These results are inconsistent with the findings of Shaban et al. (17). The results of their study showed that understanding the concept of health was good for both the students of medical sciences and the students in other fields, though that amount of understanding was true for less than $50 \%$ of the students in the two groups. Understanding the concept of health is of particular importance in choosing health care behaviors and promoting health by students. Although the students participating in the study had a low score on this, the researcher believes that the differences in time, space, and the number of participants in the groups and the tools applied to carry out the study can be the cause of differences among the results of these studies. Health behaviors are also weak for the two groups of medical and non-medical students. Khazaee et al. (18) and Hosseinin et al. (19) also reported that these behaviors are undesirable and mediocre in the students of nursing and medicine. Other studies (20-22) stated that the mean score for health-promoting behavior was acceptable. The results of various studies have been reported in a range from adverse to acceptable which indicates a weakness in students' health behaviors and their tendency toward hygienic behaviors. There was not any significant difference between the mean scores for health behaviors except for the aspects of self-care and medical care, eating habits and the students' living environment. This result is consistent with the findings of the previous studies $(17,23)$. But the results of the study conducted by Hajian et al. (12) show that the prevalence of high-risk behaviors varies according to the type of university and it is less among medical students. It was assumed that this difference would be significant since the students of medical majors become familiar with many issues regarding healthcare and thus would reach higher levels of health while the students in non-medical majors have less academic information about health issues. In addition, people morally have higher expectations from physicians and medical staff. The results show that there is a significant relationship between understanding the concept of health and health behaviors. This is consistent with the findings of Shaban et al. (17) and Hajian et al. (12). It is evident that proper understanding of the health concept has a considerable effect on an individual's awareness about and insight into health behaviors and his/her willingness to opt for such behavior (24). This variable is in fact affected by various factors including education and learning about the topic. In this study, there was not any significant relationship between one's field of study and his/her score on understanding the health concept. However, there was a significant relationship between one's field of study and his/her health behaviors. Shaban et al. (17) also achieved similar results. Results of different research studies indicate that it is not education in medical sciences majors only that would lead to the promoting of healthy behavior in individuals. It can be said that high risk behaviors are associated with low levels of health and well-being (24). In this study, health behaviors have been investigated in various dimensions and the results showed that the mean scores of these behaviors in the two groups did not differ significantly and the weakness is seen in their behavior. Various studies $(12,17,19,23)$ reported similar results in different dimensions. One component of health behaviors is having healthy relations with other people particularly with members of the opposite sex. More than $70 \%$ of university students did not respond to sexual performance items. However, other studies indicated that there was risky sexual behavior among university students. In a study, $20.2 \%$ (13) and in another $34.1 \%$ (16) of the participants reported having a relationship with the opposite sex. This behavior was reported to be $34.2 \%$ among the American youth in 2009 (25). Researchers believed that one of the main goals of studies is to identify the problems and provide strategies for solving problems or minimize them. Although the results of different studies indicate the strengths and weaknesses in various aspects of health behaviors, the question is, what is the use of these results? Obviously, using results in interventions to reduce risk behaviors at different levels can be beneficial. In the annual national survey conducted on adolescents and youths aged 10-24 in 42 US states about risky behavior regarding six aspects of such behavior along with the spread of obesity and asthma, it was found that the spread of risky behavior in the year 2009 has decreased compared to the year 1999. This shows the effect of planned interventions at schools and in society to reduce the risks and improve health among young people. For example, alcohol and marijuana consumption in 1999 has respectively decreased from $50 \%$ to $26.7 \%$ and from $41.8 \%$ to $20.8 \%$ in 2009 . Moreover, cigarette consumption has decreased from $34.8 \%$ to $19.5 \%$ and sexual activity from $49.9 \%$ to $34.2 \%(25,26)$.

\section{Conclusions}

The findings of this study showed that all medical and non-medical students were treated in the same way. Weaknesses in health behaviors are seen in two groups. It is recommended that health education and health promotion programs in the form of written plans and curriculum for all students be provided. In addition to conducting further research in the field of health behaviors, a national program to monitor the behavior and performance on an annual basis based on interventions is necessary. Self-reporting tool for data collection and fatigue participants were the limitations of this study. 


\section{Acknowledgments:}

Authors wish to express their thanks to Ilam University of Medical Sciences for funding this project and for providing the field of study. Authors also wish to thank all subjects for providing data in this study.

\section{Conflict of Interest:}

There is no conflict of interest to be declared.

Authors' contributions:

All authors contributed to this project and article equally. All authors read and approved the final manuscript.

\section{References:}

1) Amini Khooei N, Sheykhiani M, Fakouri Z. Coping skills with mental health of women's teachers. Sociology of women. 2011; 2(2): 103-27.

2) World Health Organization. Health promotion. Available at http://www.who.int /topics/health promotion/ en/2015.

3) Atadokht A, Ranjbar MJ, Gholami F, Nazari T. Students Drive towards Risk-Taking Behaviors and Its Relationship with Demographic Variables and Psychological Well-Being. JHC. 2013; 15(4): 50-9.

4) Baheiraei A, Mirghafourvand M. Health promotion: From Concepts to Practice. 1st ed. Tehran: Noor-eDanesh; 2011.

5) Zadeh-Mohammadi A, Ahmadabadi Z, Heidari M. Construction and assessment of psychometric features of Iranian adolescent's risk-taking scale. Iranian Journal of Psychiatry and Clinical Psychology. 2011; 17(3): 218-25.

6) Can G, Ozdilli K, Erol O. Comparison of the health-promoting lifestyles of nursing and non-nursing students in Istanbul, Turkey. Nursing Health Science. 2008; 10(4): 273-80. doi: 10.1111/j.14422018.2008.00405.x.

7) Shamsipour M, Karani BR, Mohamadpour AA, Mansouri A. Smoking status and factors affecting students' tendency to live in dormitories of Tabriz University of Medical Sciences. Journal of Qom University of Medical Sciences. 2012; 6(1): 75-82.

8) Akbari Zardkhaneh S, Yaghubi H, Shalbaf A, Abdollahpour Y, Ramazani V, Haddadi R. Risk and Protective Behaviors and Related Factors among Students of Ministry of Science. Applied Psychological Research Quarterly. 2015; 6(1): 115-35.

9) Wang D, Ou CQ, Chen MY, Duan N. Health-promoting lifestyles of university students in Mainland China. BMC Public Health. 2009; 9(1): 379. doi: 10.1186/1471-2458-9-379. PMID: 19814831, PMCID: PMC2763867.

10) Narimani A, Akbarzadeh M, Hamzeh M. Evaluation of general health in medical students of AJA University of medical sciences, 2009. Army University of Medical Sciences of the Iran. 2009; 8(1): 49-55.

11) Ulla Diez SM, Perez-Fortis A. Socio-demographic predictors of health behaviors in Mexican college students. Health Promotion International. 2009; 25(1): 85-93. doi: 10.1093/heapro/dap047. PMID: 19875462.

12) Hajian K, Khirkhah F, Habibi M. Frequency of risky behaviours among students in Babol Universities (2009). J Gorgan Uni Med Sci. 2010; 13(2): 53-60.

13) Garmaroudi GR, Makarem J, Alavi SS, Abbasi Z. Health related risk behaviors among high school students in Tehran, Iran. Payesh J. 2010; 9(1): 13-9.

14) Esmaielzadeh H, Asadi M, Miri N, Keramatkar M. Prevalence of high risk behaviors among high school students of Qazvin in 2012. Iranian Journal of Epidemiology. 2014; 10(3): 75-82.

15) Shamsipour M, Karani BR, Mohamadpour AA, Mansouri A. Smoking status and factors affecting students' tendency to live in dormitories of Tabriz University of Medical Sciences. Journal of Qom University of Medical Sciences. 2012; 6(1): 75-82.

16) Atashnafas E, Ghorbani R, Tabatabaee SM, Abdoos H, Abbas Poor S, Mahmoudian AR. Prevalent high risk behaviors and important family factors from the point of view of adolescents: A qualitative research. Journal of Family Research. 2014; 10(2): 217-33.

17) Shaban M, Mehran A, Taghlili F. Relationship between perception of health concept and health promoting behaviors: A comparative study among Tehran university medical and non-medical Students. Hayat. 2007; 13(3): 27-36. 
18) Khazaie T, Khazaie T, Kianfar S, Jamshydizadeh L. Health-promoting behavior factors among students of Birjand University of Medical Sciences. Iranian Journal of Health Education \& Promotion. 2015; 3(2): 125-32.

19) Hosseini M, Ashktorab T, Taghdisi MH. Health Promotion Lifestyle in Nursing Students: A systematic review. Health Promotion Management. 2012; 2(1): 66-79.

20) Motlagh Z, Mazloomy-Mahmoodabad SS, Momayyezi M. Study of health-promotion behaviors among university of medical science students. Zahedan J Res Med Sci. 2010; 13(4): 29-34.

21) Baghersad Z, Shirazi M, Rasouli Z. Comparative study of health promoting behaviors among nursing, midwifery and operating room students in Nursing and Midwifery School of Isfahan University of Medical Sciences. Health Promotion Management. 2016; 5(2): 31-41.

22) Mahmoodi Gh, Jahani MA, Naghavian M, Nazari A, Ahmadi N. A Study of health-promoting behaviors of medical sciences students of Islamic Azad university of Sari, Iran 2013. Iran J Health Sci. 2014; 2(2): 52 7. doi: 10.18869/acadpub.jhs.2.2.52.

23) Ramezankhani A, Rakhshani F, Ghaffari M, Ghanbari Sh, Azimi S. Comparison of health promoting behaviors in the first and fourth year students of Shahid Beheshti University of Medical and non-Medical Sciences in the academic year 92-93. Hakim Jorjani J. 2015; 2(1); 47-55.

24) Olchowski AE, Graham JW, Beverly EA, Dupkanick CW. Cigarette smoking, physical activity, and the health status of college students. Journal of Applied Social Psychology. 2009; 39(3): 683-706. doi: 10.1111/j.1559-1816.2009.00456.x.

25) Eaton DK, Kann L, Kinchen S, Shanklin Sh, Ross J, Hawkins J, et al. Youth risk behavior surveillance United States, 2009. MMWR Surveill Summ. 2010; 59(5): 1-142. PMID: 20520591.

26) Kann L, Kinchen SA, Williams BI, Ross JG, Lowry R, Grunbaum JA. Youth Risk Behavior Surveillance-United States, 1999. State and local YRBSS Coordinators. J Sch Health. 2000; 70(7): 271-85. PMID: 10981282. 